\title{
Association of Helicobacter pylori infection with Oxidized low density lipoprotein in patient with Type II Diabetes mellitus \\ Wesam Ahmed Nasif ${ }^{1,2}$, Mohammed Hasan Mukhtar ${ }^{2}$, Mohammed Mahmoud Nour Eldein ${ }^{2,3}$ \\ ${ }^{I}$ Molecular Biology Department, Genetic Engineering and Biotechnology Research Institute, Sadat University, Sadat City, Egypt. ${ }^{2}$ Biochemistry Department, Faculty of medicine, Umm Al-Qura University, Makkah, Kingdom of Saudi Arabia. \\ ${ }^{3}$ Oncology Diagnostic Unit, Faculty of medicine, Ain Shams University, Cairo, Egypt.
}

\begin{tabular}{l}
\hline A R T I C L E I N F O \\
\hline Article history: \\
Received X November 2015 \\
Accepted X December 2015 \\
Available online December 2015 \\
Keywords: \\
Helicobacter pylori, Type 2 Diabetes \\
mellitus, Oxidized low density \\
lipoprotein, enzyme linked \\
immunosorbent assay
\end{tabular}

\section{Introduction}

Helicobacter pylori (H. pylori) infection is probably one of the most common chronic

\begin{abstract}
ABS TRAC T
Background and Aims. Helicobacter pylori (H. pylori) is one of the most common chronic infections in patients with gastrointestinal disorders. Recent reports suggested that $H$. pylori might have high prevalence among patients with diabetes. This study aimed to determine and compare frequency of $H$. pylori infection in type 2 diabetes mellitus (T2DM) and non-diabetic patients. In addition to, evaluating the relationship between serum oxidized low density lipoprotein (Ox-LDL) levels in T2DM and nondiabetic patients with $H$ pylori infection. Methods. This study was conducted in 100 patients presented with history of epigastric discomfort for more than one month; 50 patients with T2DM and 50 non-diabetics. Anti-H. pylori IgG using ELISA, fasting and postprandial glucose level, glycated hemoglobin (HbAlc) and body mass index (BMI) was calculated. Serum Ox-LDL was measured using competitive sandwich enzyme immunoassay for patients and control subject. Results. Rates of H. pylori infection of T2DM and non-diabetic were $66 \%$ and $58 \%$, respectively, $(p=0.001)$. H. pylori $\operatorname{Ig} G$ antibody was not correlated with $\mathrm{HbA} 1 \mathrm{c}$ either in T2DM $(p=0.06)$ or nondiabetic $(p=0.25)$. Serum Ox-LDL level in type 2 diabetes with positive $H$. pylori infection showed a significant difference compared to diabetics with both negative $H$. pylori infection and in non-diabetics with positive $H$. pylori infection $(p=0.001)$. No correlation between Ox-LDL concentration and HbA1c in T2DM patients infected with $H$. pylori was observed $(\mathrm{r}=0.07, p=0.69)$ Conclusions. Infection H. pylori in T2DM was higher compared to non-diabetic population and appears not to be associated with glycemic control; T2DM seems to be associated with increased oxidative stress in $H$. pylori infection. Increased Ox-LDL levels suggest the mechanistic link between $H$. pylori infection combined with diabetes and increased generation of ROS and could play as an important image for high risk to atherosclerosis.
\end{abstract}

(C) 2015 Publisher All rights reserved. bacterial infections worldwide [1] and is recognized as the major acquired factor in the 
pathogenesis of chronic antral gastritis, peptic ulcer disease and gastric cancer [2, 3]. Different studies reported that prevalence of chronic $H$. pylori infection associated with both gastrointestinal and extra-intestinal ailments [4, 5, and 6]. Gastrointestinal inflammation caused by $H$. pylori can influence the absorption of glucose and lipids, which are also abnormal in diabetes mellitus (DM) [6]. Diabetes has been identified as a risk factor for an extragastric manifestation of H. pylori infection $[7,8]$.

Type 2 diabetes mellitus (T2DM) is an emerging pandemic, responsible for an estimated 3.8 million adult deaths worldwide [9]. The pathogenesis of T2DM is complex, with risk factors associated with lifestyle (e.g., diet, obesity, physical activity), genetic background and socioeconomic factors $[10,11]$. In T2DM, the pancreas can no longer produce enough insulin to overcome the cellular loss of sensitivity, resulting in the accumulation of sugar in the blood stream [12]. Identification of treatable causes of this disease will aid in the development of strategies to delay or prevent its onset or slow its progression. Recent evidence implicates the pathological involvement of inflammation in T2DM, which is an important process induced by $H$. pylori infection [13].The relationship between $H$. pylori and DM was first explored in 1989 by Simon et al [14] who found that the prevalence of $H$. pylori infection in patients with diabetes mellitus was significantly higher than in asymptomatic controls (62\% vs $21 \%$ ). The link between $H$. pylori infection and diabetes remains controversial, as some studies indicated a higher prevalence of infection in diabetic patients [15-16] while others reported no difference [17,18]. Recent evidence implicates the pathological involvement of inflammation in type 2 diabetes mellitus (T2DM), which is an important process induced by $H$. pylori infection [19]. As insulin resistance can be developed in the presence of inflammation [20] or as a result of alterations in counter regulatory hormones that affect insulin [21]. Thus, $H$. pylori may promote insulin resistance by inducing chronic inflammation and affecting insulin-regulating gastrointestinal hormones as reported by Aydemir et al [22].

Furthermore, $H$. pylori infection is strongly linked to the pathogenesis of T2DM, which is associated with a general activation of the innate immune system and a chronic cytokine-mediated state of low-grade inflammation [23]. The host immune response to $H$. pylori infection is complex and involves up regulation of several pro-inflammatory cytokines such as C-reactive protein (CRP) [24], interleukin 6 (IL-6) and tumor necrosis factor- $\alpha(\mathrm{TNF}-\alpha)$ [25] which are implicated in insulin resistance and the development of diabetes [26]. Thus, a potential relationship between $H$. pylori infection and diabetes is highly suspected. For this reason; it's expected in our study that, the implication between $H$. pylori and diabetes induces inflammation, accumulation of reactive oxygen species (ROS) and oxidative DNA damage in gastric mucosa.

Oxidative stress due to overproduction of ROS through either endogenous or exogenous insults can damage cellular macromolecules, leading to DNA damage, protein modification, lipid peroxidation and associated with the development of several diseases such as cardiovascular, chronic inflammation and cancer [27]. ROS production has been reported to be increased in DM [28] and $H$. pylori infection [5] which may directly contribute to the generation of oxidative stress via several mechanisms. $H$. pylori infection induces infiltration and activation of neutrophils and macrophages [29]. Enhanced ROS levels due to neutrophil infiltration and increased oxidative DNA damage have been reported in $H$. pylori-infected patients [29]. Moreover, neutrophil accumulation and oxidative stress at sites of $H$. pylori-mediated gastric inflammation induce enhanced localization of Ox-LDL at such gastric inflammatory lesions and increased plasma 
levels of Ox-LDL occur in patients with $H$. pylori-positive chronic gastritis [30].

On the other hand, oxidative stress can be induced in hyperglycemia status via glucose autoxidation and the formation of advanced glycation end-products (AGE) [31]. Other circulating factors that are elevated in diabetics, such as free fatty acids and leptin, also contribute to increased ROS generation [32]. Furthermore, oxidative stress has been increasingly implicated in the deterioration of pancreatic islet function [33]. Ox-LDL has been observed to be increased in diabetic patients and this may contribute to the increased atherogenesis in diabetes, regardless of normal lipid levels, Ox-LDL levels may be elevated in diabetic patients and this may be the explanation for the altered endothelial function [34]. Endothelium exposed to OxLDL develops alterations such as endothelial damage. The Ox-LDL itself activates inflammatory cells and potentiates the liberation of growth factors from monocytes/macrophage [34,35].

The previous reported studies were based on studying the role of oxidative stress in $H$. pylori and diabetes separately. However, to our knowledge, the association between diabetes and oxidative status has not been previously investigated in $H$. pylori infection. Therefore, the goal of this study was to assess the prevalence of $H$. pylori infection in patients with T2DM and non-diabetic patients and to compare the frequency of $\mathrm{H}$. pylori infection in both groups. In addition to evaluating the relationship between serum OxLDL levels in T2DM patients with $H$. pylori infection

\section{Material and Methods}

\subsection{Subjects}

This study was conducted in 100 patients with history of dyspepsia or epigastric discomfort for more than one month and where known as cases of type 2 diabetes mellitus for approximately five years duration. This study was done in collaboration between biochemistry department, faculty of medicine, Umm Al-Qura University, Makkah AlMukarama, Kingdom of Saudi Arabia and Sadat City University, Sadat City, Egypt. Patients with the following conditions were excluded from the study: Patients of type-I diabetes, pregnancy, prior $H$. pylori eradication therapy, use of antibiotics therapy, history of gastric surgery or cholecystectomy, chronic renal failure requiring dialysis treatment and patients who were diagnosed for malignancy.

The inclusion criteria of the study was investigated for T2DM and $H$. pylori infection, and divided into two groups- A and $\mathrm{B}$, as well as a control group of 50 volunteers. Group-A (labeled diabetic group) contains 50 diabetic patients known cases of T2DM with positive or negative $H$. pylori infection (40 females, 10 males, mean age 51.04 \pm 7.4 years); while group-B (labeled non diabetic group) contains 50 non diabetic patients with positive or negative $H$. pylori infection (19 females, 31 males, mean age $43.3 \pm 9.3$ years). The known cases of DM in group-A were also investigated for blood sugar levels (not for diagnostic purpose but to assess the blood sugar level that whether it is controlled or uncontrolled). Height and body weight were measured using a digital scale, and body mass index (BMI) was calculated as follows: $\mathrm{BMI}=$ body weight $(\mathrm{kg}) /$ height squared $\left(\mathrm{m}^{2}\right)$. The study protocol was approved by Ethics Review Board for Human Studies at Faculty of Medicine, Umm Al-Qurra University and conformed to the ethical guidelines of the 1975 Helsinki Declaration.

\subsection{Samples and Laboratory methods}


Blood samples were obtained following an overnight fasting period according to the diagnostic criteria of diabetes mellitus; only patients with fasting blood glucose above 126 $\mathrm{mg} / \mathrm{dL}$ or postprandial two hours after meal above $200 \mathrm{mg} / \mathrm{dL}$. Samples were withdrawn from a cubital vein into blood tubes and immediately serum was separated from the cells by centrifugation at $3000 \mathrm{r} / \mathrm{min}$ for 10 min and stored in refrigerator at $4^{\circ} \mathrm{C}$ until processed. Fasting blood sugar (FBS) level and postprandial blood sugar (PBS) level were measured using an auto analyzer (COBAS INTEGRA 400 PLUS, Roche, Germany). In addition, hemoglobinA1c (HbA1c) was measured according to DCCT (Diabetes Control and Complications Trial), as well as rapid urease test was determined to check the presence of $H$. pylori.

\subsection{Quantitative determination of Anti-H.}

\section{Pylori IgG}

H. pylori status was defined by the titer of $H$. pylori antibody using $H$. pylori $\mathrm{IgG}$ Enzyme-Linked Immunosorbent Assays (ELISA) (Ratio Diagnostics, Frankfurt, Germany) for the detection and qualitative determination of $\mathrm{IgG}$ antibodies to $H$. pylori in human serum. A value $<0.9$ is considered negative for the presence of detectable $\mathrm{IgG}$ antibody and values greater than 1.1 indicated the presence of detectable $\mathrm{IgG}$ antibody against $H$. pylori

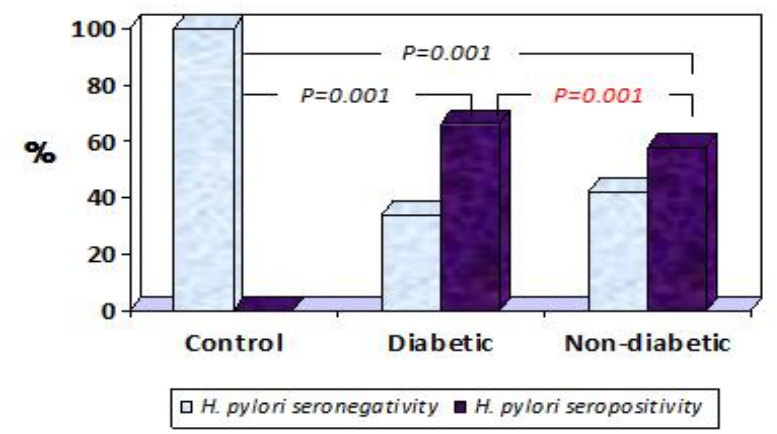

Figure 1:- The prevalence of $\mathrm{H}$. pylori infection among diabetic and non-diabetics patients of Ox-LDL in human blood serum.

\subsection{Determination of oxidized low density lipoproteins $(O x-L D L)$}

Ox-LDL was measured using the commercially available Cloud-Clone Crop Ox-LDL Competitive sandwich enzyme immunoassay technique kit (Cloud-Clone Crop., USCN Life science Inc.; Houston, TX 77082 , USA), intended to be used for quantitative measurement

The micro titer plate provided in this kit has been pre-coated with an antibody specific to Ox-LDL. Standards and samples were then added to the appropriate micro titer plate wells with a biotin-conjugated antibody specific to Ox-LDL. Avidin conjugated to Horseradish Peroxidase (HRP) was then added to each micro plate well and incubated for 30 minutes at $\quad 37 \mathrm{oC}$. After 3,3',5,5'Tetramethylbenzidine (TMB) substrate solution is added, only those wells that contain Ox-LDL, biotin-conjugated antibody and enzyme-conjugated avidin exhibited a change in color. The enzyme-substrate reaction terminated by the addition of sulphuric acid solution and the color change was assessed spectrophotometrically at a wavelength of 450 $\mathrm{nm}$. The concentration of Ox-LDL in the samples was then determined by comparing the O.D. of the samples to the standard curve.

\subsection{Statistical analysis}

All statistical analyses were done using a Statistical Package for the Social Sciences (SPSS); v.20 (SPSS Inc., Chicago, IL, USA). Continuous variables were expressed as mean $\pm \mathrm{SD}$, whereas categorical variables were expressed as numbers (percentages). Statistically significant differences between groups were determined using Student t-test and Manne Whitney U-test. Statistical comparisons between more than three groups such as data relating to circadian variation of 
Ox-LDL was performed by 1-way ANOVA. The correlation coefficient was obtained by Pearson correlation test. $\mathrm{P}$ values less than 0.05 were considered to be significant.

\section{Results}

\subsection{Baseline Characteristics}

Among 100 patients in our study, fifty patients in each group, of which $41(41 \%)$ males and $59(59 \%)$ females. The overall mean age was $47.17 \pm 9.2$ years. The mean age of male's $46.34 \pm 9.52$ and $48.37 \pm 8.91$ years old in female patients respectively. The prevalence of $\mathrm{H}$. pylori infection among diabetic and nondiabetics patients was $66 \%$ (33/50, mean age $51.79 \pm 6.9$ years) and $58 \%$ (29/50, mean age $44.86 \pm 10.08$ years) respectively. This was statistically significant ( $\mathrm{p}=0.001)$ (Figure1).

\subsection{Demographic findings in diabetic patients}

Demographic findings are shown in Table 1. Body mass index (BMI), the serum glucose level and HbAlc were found to be significantly higher in diabetic patients than in those non-diabetic patients $(p=0.0001)$. In addition, positive $\mathrm{H}$. pylori in diabetic patients was higher in HbA1c 6.93 \pm 0.69 when compared with positive $\mathrm{H}$. pylori in nondiabetic patients 3.97 $\pm 0.52 \quad(\mathrm{p}=0.001)$. Moreover, BMI was higher in diabetic patients with H. pylori infection than in those without, although it did not reach statistical significance $\quad(28.88 \pm 2.68$ vs $27.72 \pm 2.22$ $\mathrm{Kg} / \mathrm{m} 2, \mathrm{p}=>0.05)$.

3.3. Qualitative Analysis of $H$. pylori IgG antibody in diabetic and non-diabetic patients.

The $\mathrm{H}$. pylori IgG assessed antibody for confirmation of $\mathrm{H}$. pylori infection in 100 patients and 50 control. The mean $\pm \mathrm{SD}$ of $\mathrm{H}$. pylori IgG antibody in T2DM was 63.32 \pm 57.66 ; in non-diabetics was $39.5 \pm 33.90$. There was a significant difference observed between serum $\mathrm{H}$. pylori $\mathrm{IgG}$ antibody in
T2DM patients compared to non-diabetics $(\mathrm{p}=0.003)$, shown in Figure 2. Furthermore, positive $\mathrm{H}$. pylori infection in T2DM patients had the highest concentration of $\mathrm{H}$. pylori $\operatorname{IgG}$ antibody 94.52 \pm 45.9 compared to nondiabetics $66.01 \pm 17.36$ and control $0.86 \pm 0.52$, Significant difference was observed (p $<0.001$ ) (Table 1).

\subsection{Correlation between $H$. pylori IgG antibody levels and HbAlc}

The correlation between the levels of the $\mathrm{H}$. pylori $\mathrm{IgG}$ antibody and $\mathrm{HbAlc}$ is shown in Figure 3. H. pylori $\operatorname{IgG}$ antibody was not correlated with $\mathrm{HbA1c}$ either in T2DM (Pearson correlation coefficient $(r)=-0.26, p$ $=0.06)$ or in non-diabetic patients $(\mathrm{r}=0.16, \mathrm{p}=$ $0.25)$. Based on the simple linear regression of cases with and without diabetes $(n=50)$.

\subsection{Distribution of serum $O x-L D L$}

Normal circulating levels of OxLDL level as determined in normal volunteers subjects ranged between 3.81 and $69.12 \mathrm{U} / \mathrm{dL}$, mean $24.70 \pm 12.36 \mathrm{U} / \mathrm{dL}$. Serum Ox-LDL levels in patients with T2DM

106.21 $\pm 35.1 \mathrm{U} / \mathrm{dL}$ were significantly higher than in control subjects $(\mathrm{P}=0.001)$. In nondiabetic patients, serum OxLDL level $(57.76 \pm 32.1 \mathrm{U} / \mathrm{dL})$ was also significantly higher than in controls for oxidation of LDL $(\mathrm{p}=0.001)$. In addition, there was a significant difference observed between Serum Ox-LDL levels in T2DM patients compared to nondiabetics $(\mathrm{p}=0.001)$ (Figure 4).

3.6. Serum Ox-LDL Levels in T2DM and non-diabetic with positive $\mathrm{H}$. pylori infection

Serum OxLDL level in T2DM with positive H. pylori infection was $116.79 \pm 30.29 \mathrm{U} / \mathrm{dL}$, a significant difference compared to diabetics with negative $H$. pylori infection $85.68 \pm 35.69$ $\mathrm{U} / \mathrm{dL}$ or in non-diabetics with positive $\mathrm{H}$. pylori infection $72.31 \pm 33.80 \mathrm{U} / \mathrm{dL} \quad(\mathrm{p}=0.001)$ (table 2).

3.7. Correlation between $\mathrm{OxLDL}$ and HbAlc in T2DM and non-diabetic infected with $\mathrm{H}$. pylori 
There was no correlation between OxLDL concentration and $\mathrm{HbA} 1 \mathrm{c}$ either in T2DM patients infected with $\mathrm{H}$. pylori $(\mathrm{r}=0.07$, $\mathrm{p}=0.69$ ) or in non-diabetic patients infected with $\mathrm{H}$. pylori $(\mathrm{r}=0.02, \mathrm{p}=0.9)$, this correlation was shown in Figure (5).

\section{Discussion}

The link between $H$. pylori infection and diabetes remains controversial. Some studies indicated a higher prevalence of infection in diabetic patients [15-16] and other studies reported no difference $[17,18]$. Previous reports, based on serologic antibody detection, have found a high prevalence of $\mathrm{H}$. pylori infection among diabetics as compared to the general population [35, 36, and 37]. The prevalence of $\mathrm{H}$. pylori infection ranged between $30 \%$ and $80 \%$ in previously reported studies [35, 38]. There are several lines of evidence to implicate increased susceptibility to infection in diabetic patients, where the mechanisms underlying the pathogenesis of diabetes are complex, involving insulin resistance, chronic inflammation, insulin secretion deficiency as a result of pancreas $\beta$ cell dysfunction, glucotoxicity, and lipotoxicity [19].

In our study, there was a significant difference in the prevalence of $\mathrm{H}$. pylori between cases and controls $(\mathrm{p}=0.001)$, using serological method for diagnosis of $\mathrm{H}$. pylori infection. The results therefore showed that $\mathrm{H}$. pylori infection is significantly associated with T2DM in our study population. Moreover, there was a significant association between the infection incidence of $\mathrm{H}$. pylori among T2DM patients compared to non-diabetic; $66 \%$ (33/50) and 58\% (29/50) respectively $(\mathrm{p}=$ $0.001)$.

The prevalence of $\mathrm{H}$. pylori infection in diabetic patients was different in previous reports. Controversial results of prevalence rates may be related to the epidemiological distribution of infection, nonhomogeneous patient groups or the kind of diagnostic method to detect infection. A seroprevalence study performed in Netherland reported that the frequency of $\mathrm{H}$. pylori infection was higher in positive antibody titer for $\mathrm{H}$. pylori infection ( $\operatorname{IgG}>300)$ in diabetics was $76.7 \%$ compared to non-diabetics $64.8 \%$ [39, 40]. In contrast, other studies that showed no association between T2DM and $\mathrm{H}$. pylori infection. In a seroprevalence study frequency of $\mathrm{H}$. pylori infection was $33 \%$ and $32 \%$, in patients with diabetes and controls respectively [41]. Demir et al. showed that the prevalence of $\mathrm{H}$. pylori infection was $61.7 \%$ and 58.5\%, among T2DM and non-diabetics respectively [38].

Several hypotheses were presented to confirm the higher prevalence of $\mathrm{H}$. pylori infection in diabetic patients such as insulin resistance and abnormal insulin secretion were central to the development of T2DM. One of these hypothesis confirm that; $\mathrm{H}$. pylori infection brings about chronic low grade inflammation with up regulation of several cytokines such as CRP, TNF and interleukin (IL)-1 $\beta$, which may influence insulin action and pancreatic $\beta$ cell secretion. The other one; $H$. pylori-induced gastritis can potentially affect the secretion of gastric hormones, including leptin, ghrelin, gastrin, and somatostatin, which could affect insulin sensitivity and glucose homeostasis. In addition, other mechanisms and mediators may be involved in the possible causative relationship between $\mathrm{H}$. pylori infection and T2DM [19].

Oxidative stress associated with the production of ROS has been shown to play an important role in the pathogenesis of diabetes [42] and H. pylori infection [43]. Excess ROS would accelerate oxidative damage to DNA and to other macromolecules, such as proteins and lipids. The present study is one of the few studies which investigated the relationship between Ox-LDL, a marker of systemic oxidative stress with $\mathrm{H}$. pylori-positive in T2DM patients. 
Our data demonstrated that T2DM patients with positive $H$. pylori infection had much higher levels of serum Ox-LDL (116.79 \pm 30.29 $\mathrm{U} / \mathrm{dL}$ ) compared with their respective controls. We found no previous reported data linking between OxLDL and T2DM combined with H. pylori infection. However, Koichi Ono (2014) showed Ox-LDL levels were significantly higher in diabetic patients $(n=$ 30) than in control patients [44]. While, Kayo et al. reported no difference in Ox-LDL levels among patients with $\mathrm{H}$. pylori infection and control subjects [29]. Several studies demonstrated that Ox-LDL is a key factor in the initiation and progression of atherosclerosis [45]. Recently, positive associations between chronic H.pylori infection and coronary heart disease has been reported [46]; other studies demonstrated that diabetes mellitus considered a risk factor for atherosclerosis and asymptomatic low grade inflammation occurs prior to unconcealed vascular lesions [33]. According to these hypotheses, atherosclerosis is considered a process involving the interplay of inflammation and oxidative stress.

Our data also indicated that there was a significant difference observed between serum Ox-LDL levels in T2DM patients with positive $\mathrm{H}$. pylori infection compared to nondiabetics with positive H. pylori infection. Our result is supported by the report of Toshima et al. which indicated a significant increase in plasma Ox-LDL in diabetics [47]. In addition, Koichi Ono has shown increased susceptibility of LDL to oxidation in diabetics [44]. Although, there were other reports indicating no increase in Ox-LDL in diabetics [48, 49]. A potential explanation for these discrepant results lies in the hypothesis that patients with $\mathrm{DM}$ are more predisposed to infections and severe diseases because of cellular immunity disorders and phagocyte dysfunction caused by hyperglycemia and decreased vascularization. Therefore, patients with DM accompanied with $\mathrm{H}$. pylori infection support the concept that oxidative stress associated with neutrophil accumulation and activation plays a role in the inflammatory process [29]. Myeloperoxidase (MPO) a strong pro-oxidant enzyme released from activated neutrophils, has been found to be capable of oxidizing LDL [50]. These hypotheses suggest the possibility that MPO secreted from activated neutrophils in $\mathrm{H}$. pylori-mediated gastritis lesions may induce LDL oxidation.

There was no correlation between serum OxLDL levels and HbA1c in T2DM ( $\mathrm{r}=0.07$, $\mathrm{p}=0.69)$ and non-diabetic $(\mathrm{r}=0.02, \mathrm{p}=0.9)$ patients with positive H. pylori. Koichi Ono and Toshima et al. also found no correlation between plasma Ox-LDL and HbA1c levels in diabetic patients than in non-diabetic patient $[44,47]$. Moreover, our data showed no correlation between serum Ox-LDL levels and positive $H$. pylori and negative $H$. pylori infection in diabetic group. In summary, the present study suggests that infection $\mathrm{H}$. pylori in T2DM was higher compared to nondiabetic population and appears not to be associated with glycemic control; T2DM seems to be associated with increased oxidative stress in H. pylori infection. This is the first report as known of a direct association between serum Ox-LDL levels and T2DM patients companied with positive $\mathrm{H}$. pylori infection. Furthermore, we observed that significantly elevated serum Ox-LDL levels in T2DM patients with positive $H$. pylori infection, suggesting hypothesis that high serum level of Ox-LDL levels in T2DM patients with positive $H$. pylori infection considered as a risk factor to atherosclerotic vascular disease and further studies are needed to confirm this hypothesis.

\section{Acknowledgment}

This study was supported by Deanship of Scientific Research, Medicine and Medical Sciences Research Unit, Umm Alqura University, Foundation Grant no. 43409027.

\section{References}


1. Bi-Ling Yang, Chun Yeh, Wei-Gang Kwong, Shou-Dong Lee: A novel one-step Helicobacter pylori saliva antigen test. Journal of the Chinese Medical Association 2015, 78: 96-100.

2. Wang $\mathrm{F}, \mathrm{Fu} \mathrm{Y}, \mathrm{Lv} \mathrm{Z}$ : Association of Helicobacter pylori infection with diabetic complications: a meta-analysis. Endocrine research 2014, 39: 7-12.

3. Zhu Y, Zhou X, Wu J, Su J, Zhang G: Risk factors and prevalence of Helicobacter pylori infection in persistent high incidence area of gastric carcinoma in Yangzhong city. Gastroenterology Research and Practice 2014, 2014, Article ID 481365, 10 pages.

4. Wong F, Rayner-Hartley E, Byrne MF: Extraintestinal manifestations of Helicobacter pylori: A concise review. World J Gastroenterol. 2014, 20: 1195011961.

5. Masoud S, Yousef R, Zahra S, Fariba K, Mohammad R: The effect of Helicobacter pylori infection on oxidative stress status in erosive reflux disease. Medical Journal of Dr. D.Y. Patil University 2013, 6: 55-59.

6. Tsang KW, Lam

SK:

Extragastroduodenal conditions associated with Helicobacter pylori infection. Hong Kong Med J 1999, 5: 169-174.

7. Malamug LR, Karnchanasorn R, Samoa R, Chiu $\mathrm{KC}$ : The role of Helicobacter pylori seropositiv ity in insulin sensitivity, beta cell function and abnormal glucose tolerance. Scientifica 2014, 2014, Article ID 870165, 10 pages.

8. Guo X, Zhao BH, Zhang MX: Risk factors of Helicobacter pylori infection among adults in Northern China. HepatoGastroenterology 2011, 58: 306 -310.

9. Van Dieren S, Beulens JW, van der Schouw YT, Grobbee DE, Neal B. The global burden of diabetes and its complications: an emerging pandemic. Eur J Cardiovasc Prev Rehabil 2010; 17 Suppl 1: $\mathrm{S} 3-\mathrm{S} 8$.

10. Qi L, Hu FB, Hu G. Genes, environment, and interactions in prevention of type 2 diabetes: a focus on physical activity and lifestyle changes. Curr Mol Med 2008; 8: 519-532.

11. Agardh E, Allebeck P, Hallqvist J, Moradi T, Sidorchuk A.Type 2 diabetes incidence and socio-economic position: a systematic review and meta-analysis. Int $\mathrm{J}$ Epidemiol 2011; 40:804-818.

12. Papamichael KX, Papaioannou G, Karga H, Roussos A, Mantzaris GJ. Helicobacter pylori infection and endocrine disorders: is there a link? World J Gastroenterol 2009; 15: 2701-2707.

13. Donath MY, Shoelson SE. Type 2 diabetes as an inflammatory disease. Nat Rev Immunol 2011; 11: 98-107.

14. Simon L, Tornóczky J, Tóth M, Jámbor M, Sudár Z: The significance of Campylobacter pylori infection in gastroenterologic and diabetic practice. Orvosi hetilap 1989, 130: 1325-1329.

15. Devrajani BR, Shah SZ, Soomro AA, Devrajani T: Type 2 diabetes mellitus: A risk factor for Helicobacter pylori infection: A hospital based casecontrol study. Int J Diabetes Dev Ctries 2010, 30: 22-26.

16. Bener A, Micallef $\mathrm{R}$, Afifi M, Derbala M, Al-Mulla HM, Usmani MA: Association between type 2 diabetes mellitus and Helicobacter pylori infection. Turk J Gastroenterol 2007, 18: 225-229.

17. Stanciu OG, Trifan A, Sfarti C, Cojocariu C, Stanciu C: Helicobacter pylori infection in patients with diabetes mellitus. Rev Med Chir Soc Med Nat Iasi 2003, 107: 5965.

18. Anastasios R1, Goritsas C, Papamihail C, Trigidou R, Garzonis $\quad P$, Ferti A: Helicobacter pylori infection in diabetic 
patients: prevalence and endoscopic findings. Eur J Intern Med 2002, 13: 376.

19. He C, Yang Z, Lu NH: Helicobacter pylori infection and diabetes: Is it a myth or fact?. World J Gastroenterol 2014, 20: 4607-4617.

20. Shinohara K, Shoji T, Emoto M, Tahara $\mathrm{H}$, Koyama H, Ishimura E, Miki T, Tabata T, Nishizawa Y: Insulin resistance as an independent predictor of cardiovascular mortality in patients with end-stage renal disease. J Am Soc Nephrol 2002, 13:18941900.

21. Moss SF, Legon S, Bishop AE, Polak JM, Calam J: Effect of Helicobacter pylori on gastric somatostatin in duodenal ulcer disease. Lancet 1992, 340: 930-932.

22. Aydemir S, Bayraktaroglu T, Sert M, Sokmen C, Atmaca H, Mungan G, Gun BD, Borazan A, Ustundag Y: The effect of Helicobacter pylori on insulin resistance. Dig Dis Sci 2005, 50: 2090-2093.

23. Jackson L, Britton J, Lewis SA, McKeever TM, Atherton J, Fullerton D, Fogarty AW: A population-based epidemiologic study of Helicobacter pylori infection and its association with systemic inflammation. Helicobacter 2009, 14:108-113.

24. Hamed SA, Amine NF, Galal GM, Helal SR, Tag El-Din LM, Shawky OA, Ahmed EA, Abdel Rahman MS: Vascular risks and complications in diabetes mellitus: the role of Helicobacter pylori infection. $\mathbf{J}$ Stroke Cerebrovasc Dis 2008, 17: 86-94.

25. Kathryn EW and Gökhan $\mathrm{SH}$ : Inflammation, stress, and diabetes. J Clin Invest 2005, 115: 1111-1119.

26. Ma Y, Zhang L, Rong S, Qu H, Zhang Y, Chang D, Pan H, Wang W: Relation between Gastric Cancer and Protein Oxidation, DNA Damage, and Lipid Peroxidation. Oxidative Medicine and Cellular Longevity 2013, 2013, Article ID 543760, 6 pages.
27. Marin MT, Dasari PS, Tryggestad JB, Aston CE, Teague AM, Short KR: Oxidized HDL and LDL in adolescents with type 2 diabetes compared to normal weight and obese peers. J Diabetes Complications 2015， 29: 67985.

28. Aslan M, Horoz M, Nazligul Y, Bolukbas C, Bolukbas FF, Selek S, Celik H, Erel O: Insulin resistance in $\mathrm{H}$ pylori infection and its association with oxidative stress. World J Gastroenterol 2006, 14: 6865-6868.

29. Kayo S, Ohsawa M, Ehara S, Naruko T, Ikura Y, Hai E, Yoshimi N, Shirai $\mathrm{N}$, Tsukamoto $\mathrm{Y}$, Itabe $\mathrm{H}$, Higuchi $\mathrm{K}$, Arakawa T, Ueda M: Oxidized lowdensity lipoprotein levels circulating in plasma and deposited in the tissues: Comparison between Helicobacter pyloriassociated gastritis and acute myocardial infarction. American Heart Journal 2004, 148: 818-825.

30. Nowotny K, Jung T, Höhn A, Weber D, Grune T: Advanced Glycation End Products and Oxidative Stress in Type 2 Diabetes Mellitus. Biomolecules 2015, 5: 194-22.

31. Tangvarasittichai S: Oxidative stress, insulin resistance, dyslipidemia and type 2 diabetes mellitus. World J Diabetes 2015, 6: 456-480.

32. Pi J, Bai Y, Zhang Q, Wong V, Floering LM, Daniel K, Reece JM, Deeney JT, Andersen ME, Corkey BE, Collins S: Reactive oxygen species as a signal in glucose stimulated insulin secretion. Diabetes 2007, 56: 1783-1793.

33. Aqeela H, Hamid JQ, Shahid H, Waqas S: Assessment of oxidized low density lipoprotein, as atherosclerosis risk marker in type 1 diabetic children with short history of diabetes mellitus. Pak J Physiol 2010, 6:32-35. 
34. Nagy L, Tontonoz P, Alvarez JG, Chen H, Evans RM: Oxidized LDL regulates macrophage gene expression through ligand activation of PPAR- $\gamma$. Cell 1998, 93: 229-240.

35. Gasbarrini A, Ojetti V, Pitocco D, De Luca A, Franceschi F, Candelli M, Sanz Torre E, Pola P, Ghirlanda G, Gasbarrini G: Helicobacter pylori infection in patients affected by insulin-dependent diabetes mellitus. Eur J Gastroenterol Hepatol 1998, 10: 469-472.

36. Oldenburg B, Diepersloot RJ, Hoekstra JB: High seroprevalence of Helicobacter pylori in diabetes mellitus patients. Dig Dis Sci 1996, 41: 458-461.

37. Gulcelik NE, Kaya E, Demirbas B, Culha C, Koc G, Ozkaya M, Cakal E, Serter R, Aral Y: Helicobacter pylori prevalence in diabetic patients and its relationship with dyspepsia and autonomic neuropathy. J Endocrinol Invest. 2005, 28: 214-217.

38. Demir M, Gokturk HS, Ozturk NA, Kulaksizoglu M, Serin E, Yilmaz U: Helicobacter pylori prevalence in diabetes mellitus patients with dyspeptic symptoms and its relationship to glycemic control and late complications. Dig Dis Sci 2008, 53: 2646-2649.

39. Shrestha R, Koirala K, Raj KC, Batajoo KH: Helicobacter pylori Infection among Patients with Upper Gastrointestinal Symptoms: Prevalence and Relation to Endoscopy Diagnosis and Histopathology. J Family Med Prim Care 2014, 3: 154158.

40. Talebi-Taher M, Mashayekhi M, Hashemi MH, Bahrani V: Helicobacter pylori in Diabetic and Non-Diabetic Patients with Dyspepsia. Acta Medica Iranica 2012, 50: 315-318.

41. Xia HH, Talley NJ, Kam EP, Young LJ, Hammer J, Horowitz M: Helicobacter pylori infection is not associated with diabetes mellitus, nor with upper gastrointestinal symptoms in diabetes mellitus. Am J Gastroenterol 2001, 96: 1039-1046.

42. Ferdinando G, Michael B, Ann Marie S, Guest E: Oxidative Stress and Diabetic Complications. Circ Res. 2010, 107: 10581070.

43. Johannes GK, Arnoud HM, Ernst JK: Pathogenesis of Helicobacter pylori Infection. Clin Microbiol Rev. 2006, 19: 449-490.

44. Koichi O: Effect of glycemic control on plasma oxidized low density lipoprotein levels in diabetics. Science Journal of Clinical Medicine 2014, 3: 91-97.

45. Maiolino G, Rossitto G, Caielli P, Bisogni V, Rossi GP, Calò LA: The Role of Oxidized Low-Density Lipoproteins in Atherosclerosis: The Myths and the Facts. Mediators Inflamm 2013, 2013, Article ID 714653, 13 pages.

46. Vafaeimanesh J, Hejazi SF, Damanpak V, Vahedian M, Sattari M, Seyyedmajidi M: Association of Helicobacter pylori Infection with Coronary Artery Disease: Is Helicobacter pylori a Risk Factor?. The Scientific World Journal 2014, 2014, Article ID 516354, 6 pages.

47. Toshima S, Hasegawa A, Kurabayashi M, Itabe H, Takano T, Sugano J, Shimamura K, Kimura J, Michishita I, Suzuki T, Nagai R: Circulating Oxidized Low Density Lipoprotein Levels A Biochemical Risk Marker for Coronary Heart Disease. Arteriosclerosis Thrombosis and Vascular Biology 2000, 20: 2243-2247.

48. Ehara S, Ueda M, Naruko T, Haze K, Itoh A, Otsuka M, Komatsu R, Matsuo T, Itabe H, Takano T, Tsukamoto Y, Yoshiyama M, Takeuchi K, Yoshikawa J, Becker AE: Elevated levels of oxidized low density lipoprotein show a positive relationship with the severity of acute coronary 
syndromes. Circulation 2001, 103: 19551960.

49. K Kugiyama K, Sugiyama S, Soejima H, Kawano H, Sakamoto T, Takazoe $\mathrm{K}$, Ogawa $\mathrm{H}$, Doi $\mathrm{H}$, Yasue $\mathrm{H}$ : Increase in plasma levels of oxidized low-density lipoproteins in patients with coronary spastic angina. Atherosclerosis 2001, 154: 463-467.

50. Carr AC, McCall MR, Frei B: Oxidation of LDL by Myeloperoxidase and reactive nitrogen species reaction pathways and antioxidant protection" Arterioscler Thromb Vasc Biol. 2000, 20:1716-1723.

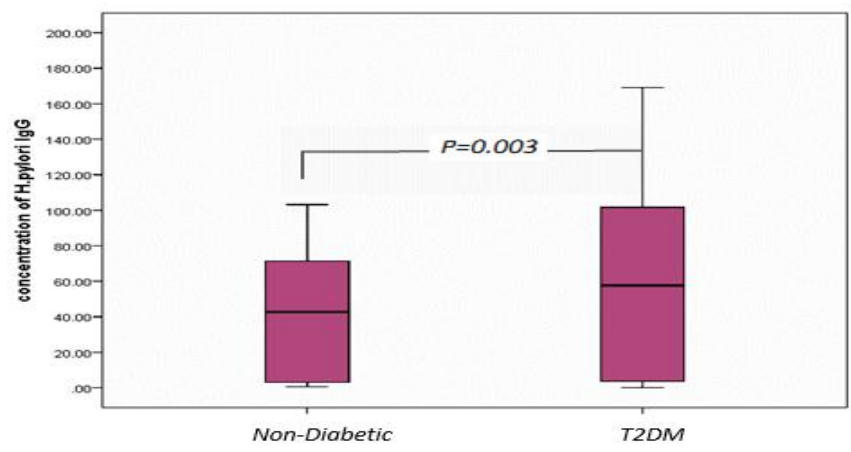

Figure 2:-Box plot for $H$. pylori IgG concentration in non-diabetic and diabetic patients.

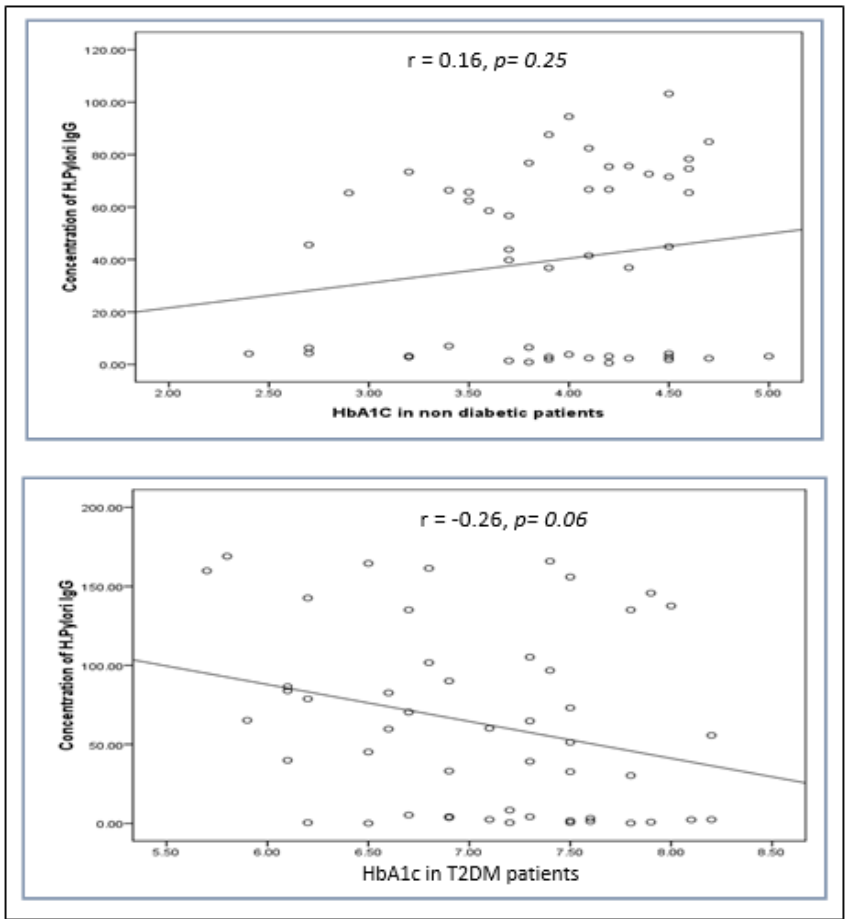

Figure 3:- Correlation between $\mathrm{HbA} 1 \mathrm{c}$ in non-diabetic and diabetic patients measured by ELISA (expressed in $\%$ ) and concentration of $H$. pylori $\operatorname{IgG}$ (expressed in $\mathrm{U}$ ). The levels of $H$. pylori IgG (y axis) were correlated with those of $\%$ HbAlc (x axis). No association was observed in two groups. Based on the simple linear regression of cases with $\mathrm{HbA1c}(\mathrm{n}=50$ for each group).

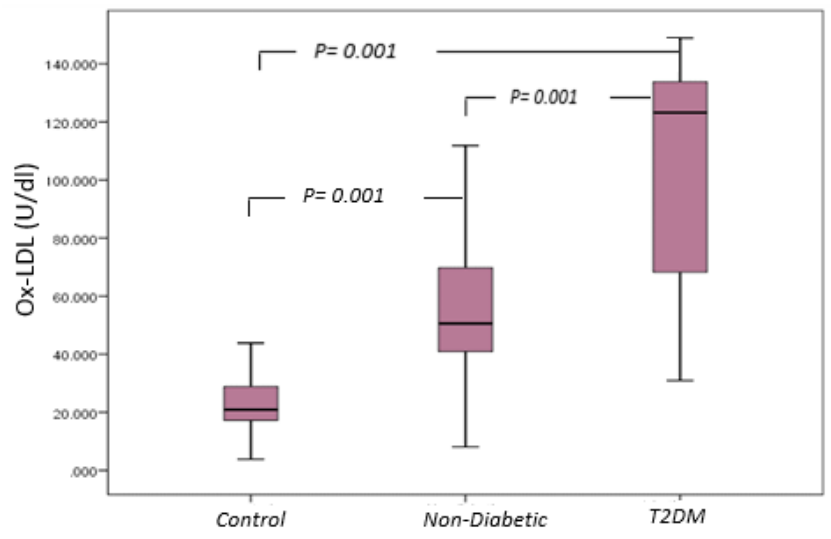

Figure 4: - Box plot for oxidized LDL in non-diabetic, diabetic patients and control. The box represents the interquartile e range. The whiskers indicate the highest and lowest values, and the line across the box indicates the median value. Overall significance of differences between non-diabetic and diabetic group was determined by $t$-test.

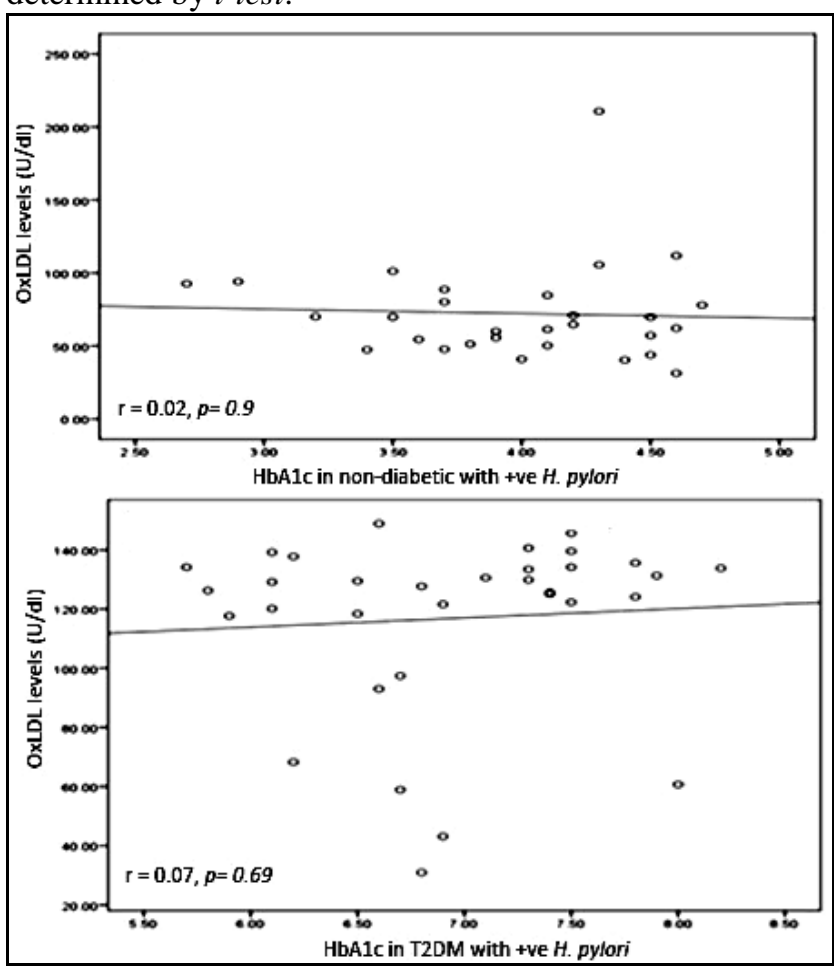

Figure 5:- Correlation between HbA1c in non-diabetic and diabetic patients with positive $H$. pylori (expressed in \%) and Oxidized LDL (expressed in U/dL). The levels of Ox-LDL (y axis) were correlated with those of HbA1c (x axis). No association was observed between HbA1c in non-diabetic and diabetic patients with positive $H$. pylori and Ox-LDL. Based on the simple linear regression of cases with positive $H$. pylori in non-diabetic and diabetic patients. 
Table (1):- Demographic and biochemical characteristic in diabetic and non- diabetic patients with (+ Ve) H. pylori and (- Ve) H. pylori infection

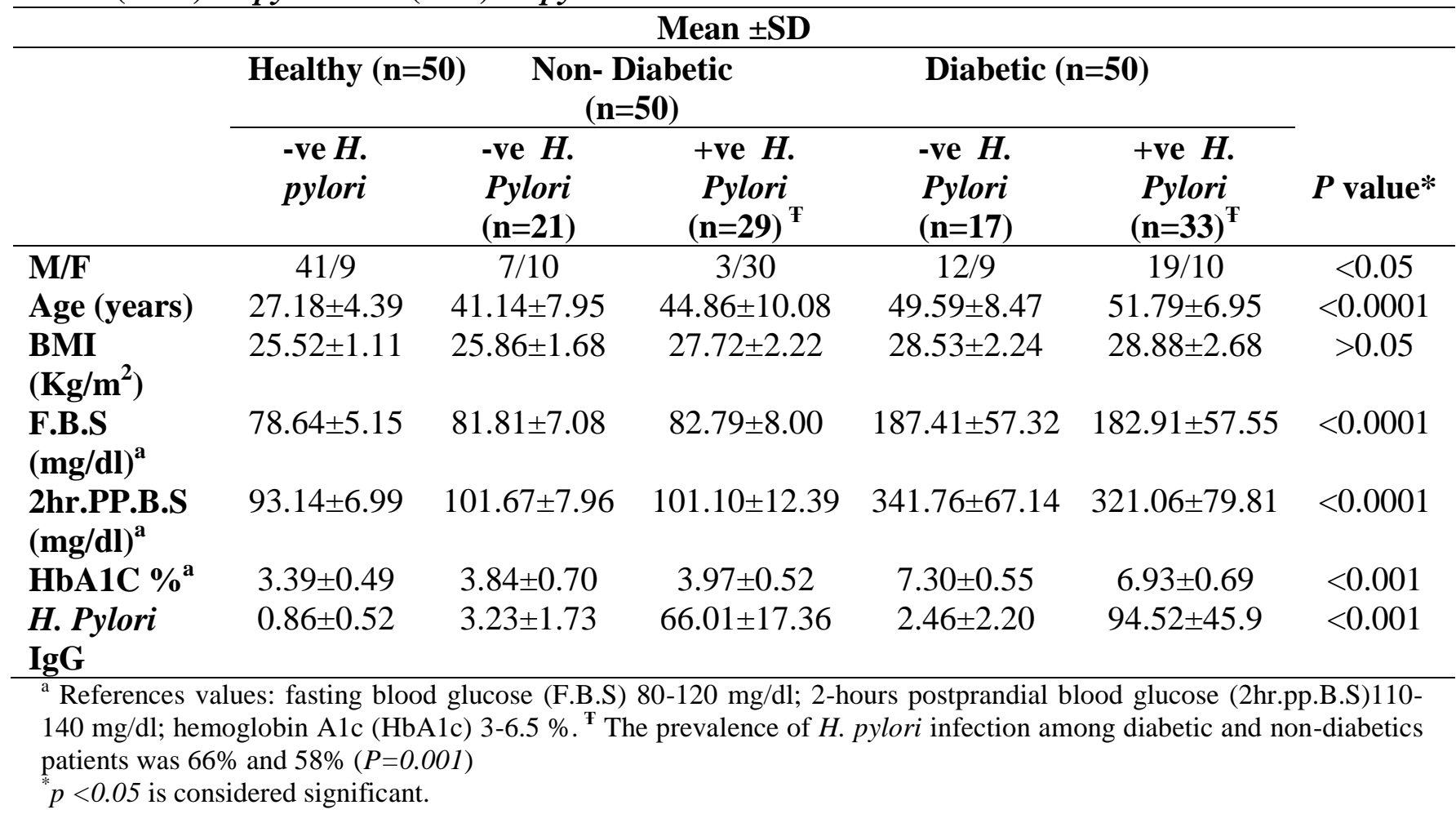

Table (2):-Distributions of Ox-LDL levels in diabetic and non- diabetic patients with (+Ve) $\boldsymbol{H}$. pylori or (-Ve) $H$. pylori infection.

\section{Mean \pm SD}

\begin{tabular}{|c|c|c|c|c|c|c|}
\hline & \multirow{2}{*}{$\begin{array}{c}\begin{array}{c}\text { Healthy } \\
(\mathrm{n}=50)\end{array} \\
\text {-ve } H \cdot \text { pylori }\end{array}$} & \multicolumn{2}{|c|}{ Non- Diabetic $(\mathrm{n}=50)$} & \multicolumn{2}{|c|}{ Diabetic $(n=50)$} & \multirow[b]{2}{*}{ P value } \\
\hline & & $\begin{array}{l}\text {-ve } H . \\
\text { Pylori } \\
(\mathrm{n}=21)\end{array}$ & $\begin{array}{c}\text { +ve } H . \\
\text { Pylori } \\
(\mathrm{n}=29)\end{array}$ & $\begin{array}{c}\text {-ve } \begin{array}{c}H . \text { Pylori } \\
(n=17)\end{array} \\
\text { (n=17 }\end{array}$ & 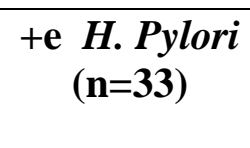 & \\
\hline $\begin{array}{l}\text { Ox-LDL } \\
\text { (U/dL ) }\end{array}$ & $24.70 \pm 12.36$ & $37.68 \pm 15.53$ & $72.31 \pm 33.80$ & $85.68 \pm 35.69$ & $116.79 \pm 30.29$ & 0.001 \\
\hline
\end{tabular}

